Nereo Zamperetti Pasquale Piccinni

\section{Intensivists managing end-of-life care: dwarfs without giants' shoulders to stand upon}

Received: 29 June 2010

Accepted: 30 June 2010

Published online: 6 August 2010

(C) Copyright jointly held by Springer and ESICM 2010

This editorial refers to the article available at: doi:10.1007/s00134-010-1953-y.

N. Zamperetti $(\bullet) \cdot$ P. Piccinni

Department of Anesthesia and Intensive Care Medicine,

San Bortolo Hospital, Via Rodolfi, 37, 36100 Vicenza, Italy

e-mail: nereo.zamperetti@ulssvicenza.it

Tel.: +39-0444-753508

Fax: +39-0444-753508

Dicebat Bernardus Carnotensis nos esse quasi nanos gigantium humeris insidentes, ut possimus plura eis et remotiora videre, non utique proprii visus acumine, aut eminentia corporis, sed quia in altum subvenimur et extollimur magnitudine gigantea.

Bernard of Chartres used to say that we are like dwarfs on the shoulders of giants, so that we can see more than they, and things at a greater distance, not by virtue of any sharpness on sight on our part, or any physical distinction, but because we are carried high and raised up by their giant size.

John of Salisbury, Metalogicon (1159)

In the past few decades, medicine-and intensive care in particular-has achieved great results. The introduction of intensive care supports caused a biological revolution: not only have previously unknown clinical conditions (brain death, vegetative state) appeared, but above all manipulating the process of dying has become possible: for the first time in the history of mankind, failing breathing can be supported, and a stopping heart can be restarted. This possibility of intervention calls for responsibility, as interfering in the process of dying is not always in the interest of the dying patient. Indeed, this ability is so new and revolutionary that our society is still trying to understand the extent and the meaning of what is happening, also in order to regulate it.

\section{Tricky situations}

Intensive supports differ from other forms of therapy. Such supports tend to self-justify for the mere reason of being (at least temporarily) life-saving. They also tend to expand from the acute to the chronic phase of the illness and from single- to multi-organ support. Their management is often hindered by prognostic uncertainty, as the available prognostic indexes cannot always predict the outcome of the individual patient with sufficient accuracy to make end-of-life decisions. On the other hand, outcomes (conscience, dependence on others, etc.) rarely correspond with black-and-white situations, but are more often confined within an ill-definable spectrum of grey. Finally, decisions of supports limitation are made even more difficult, at least from a psychological point of view, by the usual temporal correlation with the death of the patient. However, the concept that continued aggressive care may not always be beneficial is widely recognized [1]. In this sense, decisions about starting, maintaining, increasing or stopping life-supporting therapies can be extremely difficult.

In this issue of Intensive Care Medicine, Van der Hoven et al. [2] present the cases of two nonterminal ICU patients who requested forgoing of intensive supports and terminal palliation.

The history of the second patient is particularly interesting: a 58-year-old ventilator-dependent quadriplegic patient who repeatedly requested forgoing of artificial ventilation and terminal sedation. 
Such a request would be granted in many countries, but in different ways.

In The Netherlands, for instance, even active euthanasia is possible [2]. On the contrary, in Israel, honoring such a request would be more difficult. In this country, withholding (not starting) intensive supports is permitted, but withdrawing (stopping) them is forbidden. Timerregulated ventilators have to be set in order to allow withdrawing of ventilation by transforming continuous support into an intermittent one, as clinicians are not allowed to turn off a ventilator, but they can refrain from restarting it when it stops because of the preset timer [3].

In the majority of Western countries, the request of a competent patient to forgo intensive supports would be granted on the grounds that, when clinicians justifiably withdraw life-sustaining treatment, they allow patients to die but do not cause, intend or have moral responsibility for the patient's death. However, this is not always so simple and direct.

In Italy, Piergiorgio Welby, a quadriplegic patient dependent on continuous artificial ventilation, asked to be weaned from the ventilator and to be allowed to die. Some clinicians refused to grant this request, given the unclear state of Italian laws; at last, an intensivist honored his wishes, granting him adequate palliative sedation. In the following legal trial [4], the court considered the clinician's action as amounting to the crime of homicide on request (omicidio di consenziente). However, the clinician was not convicted because the fulfilment of a professional obligation (honoring the patient's valid request to forgo an unwanted medical treatment, which is a constitutional right) was recognized, according to article 51 of the Italian penal code. In practice, the court acknowledged that: (a) at the patient's valid request, the clinician can let a patient die by withdrawing a vital support; (b) such an action is not substantially different-in legal terms - from homicide upon request; and (c) the clinician is not convictable because of the justifying reason of the fulfilment of a professional obligation. In this way, the court admitted that - even in the absence of a specific law-the patient's constitutionally recognized right of refusing every unwanted medical treatment positively counterbalances the clinician's duty to safeguard the patient's life (a situation which has strong legal and moral implications and demands great responsibility).

Now, let us go further and imagine that our quadriplegic patient had been successfully weaned from the artificial ventilator but still finds his life intolerable because of complete dependence on others for every daily activity and total absence of privacy. He consequently could request his physician to administer him a lethal dose of drug in order to die a painless death. Apart from a few countries in the world (The Netherlands, Belgium, etc.), this request would not be granted, because active euthanasia is contrary to the law and medical ethics: physicians unjustifiably kill patients whenever they intentionally administer a lethal dose of medication.
Actually, this position is not universally shared. Intensivists have already admitted that they sometimes intentionally administered drugs to hasten death both in adults $[5,6]$ and in children [7, 8], a practice that Vincent commented on, maintaining that "...because the endresult is the same, it is hypocritical to consider the withdrawal of life support as acceptable but drug injection as unacceptable" [9]. The same position, which had been previously endorsed by philosophers such as Peter Singer, has been recently stated by Miller et al. In their paper [10], they argue that "the differential moral assessment of these two practices [withdrawing life-sustaining treatment and active euthanasia by means of a lethal injection] is based on a series of moral fictions-motivated false beliefs that erroneously characterize withdrawing lifesustaining treatment in order to bring accepted end-of-life practices in line with the prevailing moral norm that doctors must never kill patients." In particular, "in both cases patients are seeking a swift and peaceful death with physician assistance, and there is no relevant difference between these means of assisted death with respect to causation and moral responsibility for the patient's death."

Interestingly, the authors' assertions that "withdrawing life-sustaining treatment, when followed shortly by the patient's death, is a life-terminating intervention," that "the very fact that mechanical ventilation can sustain life for those patients incapable of breathing on their own implies that stopping mechanical ventilation will end the life of these patients," and that "the power to sustain life by technological means goes hand-in-hand with the power to end life when these means are withheld or withdrawn" [9] have been somehow recognized by the Italian court's consideration of forgoing of ventilation as a form of homicide upon request: only the fulfilment of a professional obligation saved the Italian intensivist from a sentence.

\section{Difficult but necessary decisions}

The state of affairs is quite confused. The real problem is that these situations, in which decisions are set more on values than on facts, are quite new, completely unknown to previous generations of clinicians and scholars. Sometimes national laws are inadequate, although the impression is that they are firmly turning towards safeguarding patient self-determination. Society is still unprepared, and patients and their families waver between irrational requests for impossible salvation and usually unmotivated fears of abuse or undignified overtreatment.

Previous generations had a much easier task, as they could take advantage of centuries of previous experiences. As Bernard of Chartres said, they were like dwarfs standing on the shoulders of giants, so that they could 
benefit from the thoughts of many generations and even go further. However, the present situation is quite different, as the possibility of manipulating the process of dying is a total novelty, in relation to which previous concepts and reflections risk being totally inadequate. Nowadays, the border between life and death can be very narrow, and the moment of death usually depends no more on the untouchable laws of nature but more often on clinicians' decisions about starting, maintaining, increasing or stopping life-supporting therapies.

A full understanding of the problem and a clear definition of rights and duties of all involved subjects will probably require many years of public reflection.

In the meantime, as decisions have to be made daily (and sometimes nightly, by clinicians on call who are left alone with the responsibility for the choice), some points should be considered.

As for the decision-making process, something we can learn from the ancients is the concept of phronesis, the virtue of practical thought, or practical wisdom. Phronesis-which can be interpreted as the ability to decide how to achieve a certain end and also to reflect upon and to determine that end-is the capacity of making difficult decisions in situations of uncertainty. In order to make such decisions, a fundamental concept is that the aim of intensive supports is not to treat symptoms or to cure diseases, but to care for the patient. The object (better, the subject) of the curing/caring process is always the patient. The intensive supports should be used as long as they are useful to the patient, according to her/his wishes and project of life.

As for the practical implementation of a possible decision of limitation of treatments (not of care), such a limitation should be managed with great care and attention. The way things are done can be at least as important as the specific content of every action. In particular, the decision should be clear, known, and shared by all the involved subjects, and it should be reported and explained in the patient's charts. Then, every action should take into consideration the rights and needs of all the subjects involved in the care of the patient (the patient, the relatives, the health care workers).

Only in this way can we really take care of our patients.

Acknowledgments No financial funds, including departmental or institutional funding, supported the preparation of this paper.

\section{References}

1. Carlet J, Thijs LG, Antonelli M, Cassell J, Cox P, Hill N, Hinds C, Pimentel JM, Reinhart K, Thompson BT (2004) Challenges in end-of-life care in the ICU. Statement of the 5th international consensus conference in critical care, Brussels, Belgium, April 2003. Intensive Care Med 30:770-784

2. Van der Hoven B, de Groot Y, Thijsse W, Kompanje E (2010) What to do when a competent patient does not want to live anymore but is dependent on life-sustaining treatment? Experience from the Netherlands. Intensive Care Med. doi:10.1007/s00134-010-1953-y

3. Steinberg A, Sprung CL (2006) The dying patient: new Israeli legislation. Intensive Care Med 32:1234-1237

4. GUP c/o Tribunale di Roma, sent. n. 2049/07 del 23 luglio 2007, dep. il 17 ottobre 2007
5. Vincent JL (1999) Forgoing life support in western European intensive care units: the results of an ethical questionnaire. Crit Care Med 27:1626-1633

6. Sprung C, Cohen SL, Sjokvist P, Baras M, Bulow HH, Hovilehto S, Ledoux D, Lippert A, Maia P, Phelan D, Schobersberger W, Wennberg E, Woodcock T, Ethicus Study Group (2003) End-of-life practices in European Intensive Care Units. The Ethicus Study. JAMA 290:790-797

7. Cuttini $M$, Nadai M, Kaminski $M$, Hansen G, de Leeuw R, Lenoir S, Persson J, Rebagliato M, Reid M, de Vonderweid U, Lenard HG, Orzalesi M, Saracci R (2000) End-of-life decisions in neonatal intensive care: physicians' self-reported practices in seven European countries. Lancet 355:2112-2118
8. Provoost V, Cools F, Bilsen J, Ramet J, Deconinck P, Vander Stichele R, Vande Velde A, Van Herreweghe I, Mortier F, Vandenplas Y, Deliens L (2006) The use of drugs with a life-shortening effect in end-of-life care in neonates and infants. Intensive Care Med 32:133-139

9. Vincent JL (2001) Cultural differences in end-of-life care. Crit Care Med 29(suppl 2):N52-N55

10. Miller FG, Truog RD, Brock DW (2009) Moral fictions and medical ethics. Bioethics Jul 7 [Epub ahead of print]. doi:10.1111/j.1467-8519.2009. 01738.x 